\title{
Influence of light conditions on quality of hemp fiber
}

\author{
V. Kabanets, candidate of agricultural sciences \\ Institute agriculture North-East of NAAS
}

The purpose. To study influence of thickness of sowings on quality indicators of hemp fiber during their vegetation. Methods. Field, spectrometric, conventional for farming agriculture, plant growing and statistics. Results. It is fixed that plants of the crop react to the level of light provision: morphological and physiological parameters change, amount and quality of formation of bast fibres and seeds vary. Conclusions. Hemp positively reacts to the presence of straight solar illumination of leaves during vegetation. Heightening of plant stand in sowings is capable to induce conforming morphological and physiological changes of their organogenesis. The level of productivity of caulises of at different plant stand is unequal.

Key words: plant stand, length of caulis, yield of bast fibre.

Formulation of the problem. Hemp fiber is traditionally used for the textile industry. This fiber is very durable, less exposed to rotting, of retains its operational properties for a long time. Deeper studying the properties of hemp production scientists are constantly expanding the scope of application of hemp, which allows the plant to compete fully with other crops. The products of the textile industry are offered to produce paper, building materials (insulating materials, reinforced glass fiber, fillers), composites, abrasives, fuel products (granules, briquettes) and much more [1, 2].

The unique properties of technical hemp are of interest both in Ukraine and abroad. So recently, producers of hemp products in Russia, the Baltic countries and the EU have become more active $[3,4,5]$.

His main issue facing agricultural producers who would like to cultivate cannabis is how to properly adhere to all the peculiarities of the technology of cultivating this crop.

The modern technology of hemp cultivation includes a system of agro receptions aimed at increasing the yield and quality of the crop.

There are several main areas of application of hemp, and, accordingly, several ways to grow it. The article presents the results of studies on the cultivation of hemp for obtaining qualitative fibers. The cultivation of cannabis plants for this purpose has a number of its features, distinguishable from other directions, for example, to seeds.

The purpose of the research was to study the production of hemp from stems of seed quality fiber, depending on the density of their standing in the crops.

Research methodology. Field surveys were carried out under the conditions of the permanent establishment of the experimental base of the Experimental Station of Bast Cultures of the IGSS NAAN during 2014-2016, located on the outskirts of the city of Glukhov, Sumy Oblast, for the years 2014-2016. The predecessor was winter cereals. In the autumn, peeling of the stubble and subsequent plowing was carried out at a depth of $28-30 \mathrm{~cm}$, in the spring, the removal of moisture by harrowing, fertilizing in a dose of N84PI6K16, pre-sowing cultivation in the tractor T-150 and the cultivator KPS-4.2 at a depth of 7$10 \mathrm{~cm}$. After sows stopped were harrowing and dying. The sowing was carried out in the IV quarter of April using a SON-4.2 seeder, a row spacing of $45 \mathrm{~cm}$, a depth of seeding of 5-6 cm. The size of the plot is $27 \mathrm{~m}$. Repetition - two-time. The scheme of options provided for sowing rates: 0.5 million pieces / ha; 1.0 million pieces / ha; 1.5 million pieces / ha; 2.0 million pieces / ha; 2.5 million pieces / ha.

In the experiments, the following records, observations and analyzes were carried out: phonological observations of phases of growth and development of plants, structure of reproductive organs of plants; morphological description of varieties. Biological, ecological and economic properties of the cultivar Cannabis sativa were evaluated during the vegetative period by the method of state variety testing $[6,7]$. 
Statistical analysis of the research results was carried out using the applied computer program Statistica-6 $[8,9]$.

The appearance of stairs was observed in 7-8 days.

The plant height was measured in the phase of 4-5 pairs of true leaves, mass budding, mass flowering and the beginning of ripening of the seeds. Sample size was 20 plants per variation. Harvesting was carried out by the method of a test sheaf from a typical $1 \mathrm{~m}^{2}$ in a two-time repetition ( $2 \mathrm{~m}^{2}$ from each plot) to the phase of biological ripeness of plants (1st quarter of September). The yield of stems (straw), seeds, crop and fiber content was determined. The study of morphological characteristics (total length and technical length of the stem and diameter of the stem at $1 / 2$ of the technical length) was carried out on 40 plants of each variant of both repeats.

Research results and their discussion. Hemp seedlings are known to be a widely used culture. Accordingly, the technologies of their cultivation differ considerably depending on the purpose of the obtained crop. The most valuable planting hemp seedling is the fiber obtained from them. At the same time, the seeds of this culture are of value and practical application [10, 11].

Field studies carried out in 2014-2016 included, first of all, the cultivation of crop hemp seedlings to obtain qualitative fiber from their stems.

The yield of stems of hemp seeding, depending on the density of their standing in the crops was different. The lowest level of stem productivity was recorded at sites with a density of 0.5 million pcs / ha and averaged over three years of research $5.5 \mathrm{t} / \mathrm{ha}$. The highest yields were in areas with a density of 2.0 million pounds / ha $-7.2 \mathrm{t} /$ ha (table 1 ).

Table 1. Effect of hemp density on yield ( $t /$ ha) 2014-2016

\begin{tabular}{|l|l|l|l|l|l|}
\hline \multirow{2}{*}{$\begin{array}{l}\text { Density of standing } \\
\text { plants of culture, } \\
\text { million pcs. / ha }\end{array}$} & Yield, $\mathrm{t} / \mathrm{ha}$ & \multicolumn{2}{l|}{ Stem length, cent. } & \multirow{2}{*}{ He share of planting, \% } \\
\cline { 2 - 5 } & straw & seed & general & technical & \\
\hline 0,5 & 5,5 & 1,5 & 275 & 216 & 20,8 \\
\hline 1,0 & 6,4 & 1,7 & 283 & 252 & 19,5 \\
\hline 1,5 & 6,9 & 1,6 & 297 & 268 & 18,4 \\
\hline 2,0 & 7,2 & 1,4 & 322 & 299 & 17,2 \\
\hline 2,5 & 7,0 & 1,2 & 324 & 301 & 16,4 \\
\hline $\mathrm{Hip}_{0,05}$ & 0,16 & 0,011 & & & \\
\hline
\end{tabular}

The level of seed yield of hemp seedlings on crops of a continuous sowing method with such plant densities was low. This is the so-called "one-sided use" of crops, when the main product, which forms crops, is straw and the output of best fibers. Accordingly, the yield of seeds in hemp plants in such crops was $1.2-1.7 \mathrm{t} / \mathrm{ha}$.

Increasing the density of plants standing in the culture led to a decrease in their seed productivity and improvement of the quality of best fibers.

Harvest of straw hemp seedlings in the years of research on areas of different densities had unequal quality. The smallest total length of stems of hemp seedlings on average was $275 \mathrm{~cm}$. increasing the density of plants standing and indicators of optical density of crops led to a decrease in the illumination of individual plants and contributed to the growth of their height. Plants were pulled upward and reduced the index of their branching. The highest plants and, accordingly, the total length of their stems were recorded on crops of plots with a density of 2.5 million pcs / ha. The total length of the stems of the planting hemp seedlings reached an average of $324 \mathrm{~cm}$ or exceeded the crop rates, where the density was the smallest (0.5 million pcs / ha) by $49 \mathrm{~cm}(17.8 \%)$.

The difference in the quality of the obtained crop manifested itself in the indicators of the technical length of the stems of plant crops. Increasing the density of plants in crop hemp seedlings led to an 
increase in the technical length of the stems (distance from the surface of the soil to the first lower branch of the stem).

If the plants with a density of 0.5 million pounds per hectare, the average technical length of the stems for the years of research was $216 \mathrm{~cm}$, then plants with a density of 1.5 million pounds per hectare, it was $268 \mathrm{~cm}$, and for The density of 2.5 million pc / ha reached $301 \mathrm{~cm}$, or increased by $28.2 \%$, which significantly exceeds the difference in the total length of the planting hemp seedlings. Explain the increase in the difference in the indicators of the technical length of the stems may be reduced by the ability of plants to bite in connection with the deterioration of light (the flow of energy from the FAR) to plants in the depth of crops at a higher standing density. The smaller the lateral illumination of each plant, the less they collided and the more intensely carried apical (apical) growth and development to the source of radiation of solar radiation. Plants stretched out to a height and became longer (higher).

Such a reaction of crop hemp plants can be explained by a significant change in the hormonal status of tissues in the process of their growth and development. For most species of higher plants, one of the groups of phytohormones that synthesize plants (auxins, cytokines, and others) are gibberellins. It is likely that gibberellins (they are known in flowering plants for more than forty different substances) are most actively synthesized in meristem cells at apical points of the stems. It is gibberellins that accelerates the processes of linear growth of stems and shoots by stimulating the enhanced cell division and their tensile stress in light of a lack of light energy [12]. It is gibberellins that actively influence the processes of formation and stretching of cells of future knee and sclerenchyma, which form mechanical (bubble) fibers and determine their technical characteristics.

Changes in the level of energy (light) provision of young (imaturonic and virginal stages of ontogenesis) of plants with increasing density of standing and optical density of crops of hemp seedlings with different standing densities influenced various components of their vegetation. Interaction between plant plants and their competition for moisture, mineral nutrition, of access to the energy flux of the FAR (the effect of mutual shading) increased. The presence or deficiency of energy compounds (primarily ATP) in the tissues of plant cultures has an effect on the ability of plants to absorb and contain water in leaves of cells. The deficit of the required energy has affected the processes of mineral nutrition of crops.

The light regime of crops and their optical density have a direct influence on the conditions of formation, growth and development of plants under filling, which in crops with a density of standing 0,5 million pcs. / ha was on average $20,8 \%$. In crops with a maximum standing density ( 2.5 million pcs / ha), the number of plants was minimal, $16.4 \%$ or $21.2 \%$ less.

Vegetation conditions influenced not only the general and technical length of the stems in the hemp plants, but also the qualitative characteristics of the best fibers itself.

The analysis of the structure of the obtained crop reveals the corresponding patterns of changes that manifested as a result of growing crop hemp seedlings with different densities of plant standing. An important indicator, besides the level of straw productivity, is the yield index of the fiber, since this is one of the main parameters of the estimation of the organic mass of the stems of the hemp seedlings. For the density of 0.5 million pounds / ha with a yield of $5.5 \mathrm{t} / \mathrm{ha}$, the fiber yield amounted to $29.3 \%$ over the years of research. With the increase in the density and the decrease in the level of illumination of each plant in the crops there were changes in the morphology of the structure of their stalks. Due to lack of light, they reduced the level of branching, the stems were pulled up and became relatively thinner, and the number of parenchyma tissues that were performing the stocking function decreased, but a sufficient amount of mechanical fibers (collenchymas and sclerenchyma) was maintained that provided the corresponding mechanical stiffness of the stems. The proportion of mechanical tissues in such extracted stems of plant crops gradually increased and reached its maximum of $30.9 \%$ with a density of 2.0 million pcs. / ha. The next increase in plant density to 2.5 million pcs./ha tended to decrease the yield of fiber. It was $30.3 \%$, or $0.6 \%$ less than the previous density of plants standing in culture (table 2 ). 
Table 2. Effect of hemp density on technological qualities of fiber, 2014-2016

\begin{tabular}{|l|l|l|l|l|l|}
\hline $\begin{array}{l}\text { Density of } \\
\text { standing plants } \\
\text { of culture, } \\
\text { million pcs. / ha }\end{array}$ & \multirow{2}{*}{$\begin{array}{l}\text { Yield straw, } \\
\mathrm{t} / \text { ha }\end{array}$} & Entrance, \% & $\begin{array}{l}\text { Fiber quality } \\
\text { number }\end{array}$ & $\begin{array}{l}\text { The grade of } \\
\text { the fiber }\end{array}$ \\
\cline { 3 - 6 } & & & of long fiber & & \\
\hline 0,5 & 5,5 & 29,3 & 25,1 & 6,2 & 2 \\
\hline 1,0 & 6,4 & 29,7 & 25,6 & 6,2 & 2 \\
\hline 2,0 & 6,9 & 30,2 & 25,8 & 6,3 & 2 \\
\hline 2,5 & 7,2 & 30,9 & 26,2 & 6,4 & 1 \\
\hline Hip $_{0,05}$ & 7,0 & 30,3 & 26,1 & 6,4 & 1 \\
\hline
\end{tabular}

The size of the output, but not far from complete of the fiber is important, an indicator of the technological value of the stems of hemp seeding fiber. The results of the study prove that the vegetation of hemp plants in sown conditions in the conditions of full lateral and upper illumination provides the necessary level of energy supply for growing crops, the formation of branched stems, generative systems, fruits and seeds in them. However, obtained from the stems of such plants, the fiber is traditionally rather rough and short; obtaining qualitative spinning raw materials from such fibers is problematic.

Reducing the level of light of the crop hemp plants affects the formation of thinner and elongated best fibers in the stems that meet the requirements for technologically valuable long fibers. In vegetation plants with a density of 0.5 million pcs. / ha, the average yield of thin fibers was $27.1 \%$. As the density increased and the level of illumination of the planting hemp seeded to 2.0 million pounds per hectare, the output of long fibers increased by almost $1.1 \%$ and reached an average of $28.2 \%$. The next increase in the density of crops to 2.5 million pounds / ha already showed a slight tendency to decrease the yield of thin fiber by $0.1 \%$ from the level of crops with the previous density. Therefore, obtained from the stems of plants, hemp seeding fiber was responsible for quality estimates of various standardized numbers.

The fiber from the plots with a density of 0.5 and 1.0 million pcs./ha corresponded to the standardized numbers of 6.2 and had a second quality grade.

The different densities of standing of plants of culture formed not identical light (energy) regimes of crops that provided within certain limits the changes in morphological characteristics of plants of culture, their hormonal status, the level of development of lateral shoots and inflorescences and generative organs and the height of the stems. The influence on the volumes of fiber output and its technological qualities was also manifested.

The fiber obtained from the areas of hemp seedlings with a density of 2.0 and 2.5 million pounds per hectare, conformed to the standardized numbers of 6.4 and had the first quality grade. The obtained technical raw material - straw from the hemp planting plants on sites with different densities of plants standing in culture differed significantly between the variants of experiments, both in terms of the yield obtained and in terms of qualitative indicators.

From the results obtained in 2014-2016 Field and laboratory studies can draw conclusions:

1. Hemp seedlings - are plants with halophytes that react positively to the presence of direct and sufficient sunlight in the process of vegetation. Increasing the density of plant plants in crops can induce appropriate morphological and physiological changes in their organogenesis.

2. The level of yield of stems of hemp seedlings for different densities of standing was unequal. The lowest yield was recorded on crops with a standing density of 0.5 million pp./ha. $-5.5 \mathrm{t} / \mathrm{ha}$. The highest is $7.2 \mathrm{t} /$ ha for the density of 2.0 million pounds / ha. The next increase in the density did not ensure the growth of the yield of stems of plant crops. 
3. The highest indices of the total length of the stems of the hemp seedlings and, respectively, their technical length were recorded in areas with a density of 2.0 and 2.5 million pounds / ha and reached $322-324 \mathrm{~cm}$ and 299 and $301 \mathrm{~cm}$, respectively.

4. Increasing the density of the standing of the roses of the crop and, accordingly, their optical density, contributed to the reduction of the number of plants under cultivation in the hemp seedlings. At a density of 0.5 million pounds per ha, the number of paddocks was an average of $20.8 \%$, while the density of 2.5 million pounds per hectare was $16.4 \%$.

5. The output of best fibers was the highest in plants grown in crops with a density of 2.0-2.5 million pounds per hectare and reached 30.9 and $30.3 \%$. from the mass of stems hemp seedlings. Reducing the density of standing in the crops led to a decrease in the output of the fiber. At a density of 0.5 million pcs. I ha, the yield of the fiber was $29.3 \%$ or $1.0-1.6 \%$ below the level with the maximum stagnation density.

6. In the structure of best fiber, the output of the most valuable long fiber was the highest in crops with a density of 2.0-2.5 million pcs / ha and averaged over the years of research 28.2 and $28.1 \%$ It was this fiber that secured a high quality fiber number of 6.4 and a unit grade (higher quality). Sown with a density of 0.5 million pcs / ha shaped the fiber more rough and short. The fiber number was on average 6.2 and the quality metric corresponded to the second grade.

\section{References}

1. Goloborod'ko, P. A. Hemp conquer the world / P.A. Goloborod'ko, V. G. Virevets // Proposal. 1999. № 5. - S. 26-27.

2. Kabanets V. M. Branches of flax and hemp in Ukraine: the state and prospects // V. M. Kabanets. Abandoned Collection of scientific works of the Institute of Barny cultures of UAAS. - Vip. 5. Sumy: OJSC "SOD", 2009. - P. 3-7.

3. Rescuers N.I. World and domestic experience in using hemp stems / N.I. Lightweight // Light industry. - 2010. - №. 2. - P. 34-36.

4. Grotenhermen F., Karus M. Industrial hemp is not marijuana: Comments on the drug potential of fiber Cannabis // J. Int Hemp Ass. 1998. -v. 5.-№2.-P. 96.

5. Reshetnikov L.L. On the international scientific-technical. symposium "Modern technology and technology of fibrous materials" / L. L. Reshetnikov // Textile Industry, 2002. №2. - P. 17-19.

6. Methodology of expert examination of plant and plant varieties for technical and fodder availability for distribution in Ukraine (PSP) / Vinnytsia LLC "Nilan-LTD.", $2015 . \quad$ - 74 p.: http://www.tvoru.com.ua.

7. The method of examination of cannabis varieties of cultivars (Cannabis sativa L.) for difference, homogeneity and stability c.13 / Official bulletin. - K., 2012.- PP Publishing house "Phoenix". - 13 p.

8. Hermantraut ER Statistical analisis of multifactor experiments / E.R. Hermantraut. Field experiments for sustainable development of rural areas. - St. Petersburg-Pushkin, 2003. - P. 7073.

9. Afifi A.A. Statistical analysis. The approach with the use of a computer / A.A. Afifi, S.P. Eisen. Moscow: Mir, 1982. $-488 \mathrm{p}$.

10. Kabanets VM, Vyvrovets V.G., Laiko I.M. Non-narcotic crop of hemp - a culture of inexhaustible possibilities // Agrobusiness today: Informational and analytical newspaper. - K .: LLC "Publishing House" Impress-Media ". - 2012. - No. 11. - P. 30-32.

11. Kabanets V. M., Sitnik V. P., Strebul V. V. Seed productivity of hemp // Seed production. - 2009. №4. - P. 23-26.

12. Ivashchenko O., Ivashchenko O. Light supply of energy crops. // The Bulletin of Agrarian Science. K: №7.- 2008. - P. 26- 29. 